\title{
ESTUDO DAS DECISÕES DE PROCESSOS DE RESPONSABILIDADE CIVIL CONTRA CIRURGIÕES DENTISTAS DO ESTADO DE SÃO PAULO
}

\section{A STUDY ON THE JUDGMENTS OF CIVIL LIABILITY ACTIONS AGAINST DENTISTS IN THE STATE OF SÃO PAULO}

\author{
Antonio Carlos Victor Canettieri ${ }^{1}$ \\ Hebert de Moraes Neves ${ }^{2}$
}

\begin{abstract}
Resumo: O cirurgião-dentista (CD) no desempenho de sua profissão está sujeito a prestar contas sob o ponto de vista legal (responsabilidade penal, civil e administrativa), assim como no moral ou ético (responsabilidade ética). A responsabilidade civil envolve a obrigação de uma pessoa indenizar o dano causado a outra, com a intenção de estabelecer o equilíbrio patrimonial decorrente do dano. $O$ presente trabalho propôs uma análise na jurisprudência de processos de responsabilidade civil em ações promovidas contra cirurgiões-dentistas no estado de São Paulo, no período de 2015 e 2016. Foi realizado um levantamento nas bases de dados do site de tribunal de justiça (http://www.tjsp.jus.br). Após análise de 94 decisões judiciais, concluiu-se que o tratamento odontológico foi considerado como de obrigação de resultado (52\%) com responsabilidade do tipo subjetiva (51\%), e a inversão do ônus da prova ocorreu em 49\% dos casos; sendo que para cada 1.000 cirurgiões-dentistas (CDs) do estado de São Paulo, 1,1 já foi julgado em processos de responsabilidade civil. Conclui-se que o CD deveria dar maior importância ao prontuário odontológico, que deve ser muito bem descrito e apresentar o devido consentimento do paciente.
\end{abstract}

Palavras-chave: Odontologia. Responsabilidade Civil. Jurisprudência.

Abstract: The dentist in the exercise of the profession is subject to assume responsibility for unlawful acts committed (criminal, civil, ethical and administrative liability). Civil liability involves the obligation of one person to compensate the damage caused to another, with the intention of establishing an economic balance. This article proposes an analysis of the jurisprudence of civil liability cases in actions brought against dentists in the State of São Paulo, between 2015 and 2016. A survey was performed in the databases of the courts of justice (http: //www.tjsp.jus.br). After analyzing 94 jurisprudences, it was concluded that dental treatment was considered as an obligation of result (52\%) with subjective responsibility (51\%), and the inversion of the duty to prove occurred in $49 \%$ of the cases; and for every 1,000 dental surgeons (CDs) in the State of São Paulo, 1,1 has already been tried in civil liability cases. It is concluded that the dentist should take a greater care in the preparation of the dental record, which should be very well described and have the patient's consent.

Key words: Dentistry. Damage liability. Jurisprudence.

Data de submissão: 11.12 .2020

Data de aprovação: 20.04.2021

\footnotetext{
1 Docente do Curso de Odontologia da Universidade do Vale do Paraíba - Univap, E-mail: acanettieri@gmail.com.

${ }^{2}$ Bacharel em Odontologia pela Universidade do Vale do Paraíba - Univap, E-mail: neveshebert@bol.com.br.
} 
Identificação e disponibilidade:

(https://revista.univap.br/index.php/revistaunivap/article/view/2568,

http://dx.doi.org/10.18066/revistaunivap.v27i56.2568.

\section{INTRODUÇÃO}

A prestação de serviço odontológico, durante muito tempo, foi baseada no vínculo de confiança entre o cliente e profissional. Entretanto, a massificação dos serviços odontológicos, ocorrida num curto período de tempo, tem dificultado o desenvolvimento de um bom relacionamento profissional-paciente, culminando na insatisfação por parte dos clientes. Os pacientes estão também sujeitos a resultados insatisfatórios no tratamento odontológico e a geração de danos por atos odontológicos obriga o cirurgião-dentista (CD) a reparação por meio judicial (WANDERLEY E LIMA et al., 2012). Essa responsabilidade específica, a de responder pelos atos cometidos no exercício da profissão e pelos possíveis prejuízos produzidos decorrentes de um erro do profissional de saúde, pode ser enquadrada na esfera penal, civil e administrativa (SILVA et al., 2009). O magistrado fundamenta sua análise e estabelece o valor da indenização, principalmente para o dano moral, baseado nos fenômenos dolorosos e nos sofrimentos suportados pelo cliente decorrentes de um tratamento odontológico impróprio ou errôneo. O CD pode, também, ser penalizado e julgado administrativamente, pelo ato praticado, pelos Conselhos Regional e Federal de Odontologia, com base no Código de Ética Odontológica (OLIVEIRA et al., 2010).

O presente trabalho propôs o levantamento e a análise das decisões de processos de responsabilidade civil contra CDs no estado de São Paulo nos anos de 2015 e 2016.

\section{MATERIAL E MÉTODOS}

Foi realizada uma pesquisa nas bases de dados do tribunal de justiça (http://www.tjsp.jus.br), utilizando os unitermos: odontologia; cirurgião-dentista e responsabilidade civil, sobre as decisões judiciais envolvendo cirurgiões-dentistas (acórdãos). Tomou-se cuidado de verificar se as decisões não eram de um mesmo processo em momentos processuais diferentes, para que não houvesse repetição de resultado. Foi avaliado, em relação ao serviço odontológico, o tipo de obrigação assumida (de meio ou de resultado), o enquadramento do tratamento odontológico como de responsabilidade objetiva ou subjetiva, e a existência ou não da inversão do ônus de prova na lide judicial.

Também foi realizada uma consulta ao site do Conselho Federal de Odontologia -CFO (www.cfo.org.br) para identificar o número de CDs inscritos em atividade no estado de São Paulo e uma consulta ao site do Conselho Regional de Odontologia do estado de São Paulo- CROSP (www.crosp.org.br) para identificar o número de especialistas inscritos em atividade no estado de São Paulo, com intuito de determinar o coeficiente de experiência processual, procurando visualizar a relação existente entre o número de processos e a quantidade de CDs, por meio do cálculo: (número de processos / número de CDs) x 1.000 (DE PAULA, 2007; WANDERLEY E LIMA et al., 2012). O coeficiente de experiência processual foi realizado para o total de CDs em atividade no estado de São Paulo e para cada especialidade detectada nos processos judiciais estudados (implantodontia, ortodontia, prótese, endodontia, cirurgia e periodontia) (NEVES; CANETTIERI, 2017). 


\section{RESULTADOS}

No presente trabalho foram identificadas 94 decisões judiciais no estado de São Paulo, sendo 47 computadas no ano de 2016 e 47 no ano de 2015, sendo que 49 processos foram direcionados contra empresas odontológicas (pessoa jurídica), podendo ter sido considerada nessas situações a situação de responsabilidade solidária. Os processos estavam distribuídos em 35 comarcas do estado de São Paulo, no período de 2015 - 2016, sendo a da cidade de São Paulo a que mais apresentou processos contra CD (30 dos 94 acórdãos levantados), seguida por Santo André $(n=6)$ e Campinas $n=(5)$. A especialidade odontológica mais envolvida foi a Implantodontia com $42 \%$ dos casos $(n=34)$. Na sequência, as especialidades encontradas foram: Ortodontia (20\%), Prótese $(20 \%)$, Endodontia $(12 \%)$, Cirurgia $(5 \%)$ e Periodontia (1\%). Em dois processos, não foi possível detectar a especialidade envolvida. Onze processos foram direcionados para clínica geral e esses dados não foram computados na relação de especialidades. Em um caso que foi relatado como "Estética" não foi possível relacionar com alguma especialidade reconhecida pelo CFO (dentística, prótese, implantodontia) ficando, então, esse dado fora da relação. Nas decisões judiciais, $56 \%(n=53)$ dos CDs e/ou empresas odontológicas foram condenados.

Em relação ao tipo de obrigação assumida pelo $C D$, se de meio ou de resultado, em $39 \%$ dos casos essa informação não foi citada, e em $52 \%$ ( $n=49$ ) foi definida como obrigação de resultado. Considerando o tipo de responsabilidade do CD, em $34 \%$ dos casos não houve essa classificação, e em $51 \%$ foi definida como subjetiva. Em relação à inversão do ônus de prova, 46 dos processos avaliados (49\%) apresentou essa ferramenta legal, contra 13 em que tal item não foi concedido (14\%). Em $37 \%$ das decisões judiciais não foi possível detectar a existência ou não da inversão do ônus de prova (Tabela 1).

Tabela 1- Distribuição numérica e porcentual do tipo de obrigação, do tipo de responsabilidade e da existência da inversão do ônus da prova em processos judiciais de responsabilidade civil contra CDs do estado de São Paulo, no período de 2015 e 2016.

\begin{tabular}{cclc}
\hline & & N & $\%$ \\
\hline Tipo de obrigação & Meio & 8 & 9 \\
& Resultado & 49 & 52 \\
& Indefinido & 37 & 39 \\
\hline Tipo de & Objetiva & 14 & 15 \\
Responsabilidade & Subjetiva & 48 & 51 \\
& Indefinido & 32 & 34 \\
\hline Inversão de ônus de & Sim & 46 & 49 \\
prova & Não & 13 & 14 \\
& Não consta & 35 & 37
\end{tabular}

Fonte: Elaborado pelos autores. Dados coletado do Tribunal de Justiça do Estado de São Paulo (2015-2016).

$\mathrm{Na}$ análise geral das indenizações, considerando apenas os 53 processos em que o $C D$ foi condenado, $64 \%(n=34)$ foi por danos materiais e morais, $28 \%(n=15)$ apenas morais e $6 \%(n=3)$ apenas materiais e em um caso não foi possível identificar o tipo de indenização (2\%). No ano 2015 , o menor valor de indenização foi $R \$$ 
$2.439,99$ e o maior valor foi $R \$ 46.460,00$. No ano 2016 , o menor valor foi $R \$ 5.200,00$ e o maior valor foi $R \$ 32.147,00$. O valor médio indenizatório para o período avaliado foi de $R \$ 15.657,78$.

As tabelas 2 a 5 apresentam para as especialidades mais detectadas no levantamento (implantodontia, ortodontia, prótese e endodontia) o tipo de obrigação (de resultado ou de meio), a decisão judicial (condenado ou absolvido), a indenização para o paciente (moral e/ou patrimonial, no caso de o CD ter sido condenado) e o valor médio de indenização.

Tabela 2- Distribuição numérica e porcentual do tipo de obrigação, da decisão judicial, da indenização por danos materiais e/ou morais ( ${ }^{*}$ considerando apenas os casos condenados) e o valor médio da indenização, para a especialidade Implantodontia $(n=34)$.

\begin{tabular}{cccc}
\hline & & $N$ & $\%$ \\
\hline Tipo de obrigação & Resultado & 25 & 73 \\
& Meio & 01 & 4 \\
& Não apresentado & 08 & 23 \\
\hline Decisão judicial & Condenado* & 25 & 73 \\
& Absolvido & 09 & 27 \\
\hline Indenização por $_{\text {danos * }}$ & Materiais e morais & 16 & 64 \\
& & & 8 \\
& Materiais & 02 & 24 \\
& Morais & 06 & 4 \\
\hline
\end{tabular}

\begin{tabular}{cc}
\hline $\begin{array}{c}\text { Valor médio da } \\
\text { indenização }\end{array}$ & $\mathrm{R} \$ 15.111,49$ \\
\hline
\end{tabular}

Fonte: Elaborado pelos autores. Dados coletado do Tribunal de Justiça do Estado de São Paulo (2015-2016).

Tabela 3 - Distribuição numérica e porcentual do tipo de obrigação, da decisão judicial, da indenização por danos materiais e/ou morais ( ${ }^{*}$ considerando apenas os casos condenados) e o valor médio da indenização, para a especialidade Ortodontia $(n=15)$.

\begin{tabular}{cccc}
\hline & & $\mathrm{N}$ & $\%$ \\
\hline Tipo de obrigação & Resultado & 04 & $\mathbf{2 7}$ \\
& Meio & 01 & 7 \\
& Não apresentado & 10 & 66 \\
\hline Decisão judicial & Condenado* & 05 & 34 \\
& Absolvido & 10 & 66 \\
\hline Indenização por danos $^{*}$ & Materiais e morais & 03 & 60 \\
& Materiais & 0 & - \\
& Morais & 02 & 40 \\
& Não apresentado & 0 & -
\end{tabular}

\begin{tabular}{ll}
\hline $\begin{array}{l}\text { Valor médio da } \\
\text { indenização }\end{array}$ & $\mathrm{R} \$ 20.238,75$ \\
\hline
\end{tabular}

Fonte: Elaborado pelos autores. Dados coletado do Tribunal de Justiça do Estado de São Paulo (2015-2016). 
Tabela 4 - Distribuição numérica e porcentual do tipo de obrigação, da decisão judicial, da indenização por danos materiais e/ou morais ( ${ }^{*}$ considerando apenas os casos condenados) e o valor médio da indenização, para a especialidade Prótese $(n=15)$.

\begin{tabular}{cccc}
\hline & & $N$ & $\%$ \\
\hline Tipo de obrigação & Resultado & 05 & 36 \\
& Meio & 01 & 7 \\
& Não apresentado & 09 & 57 \\
\hline Decisão judicial & Condenado* & 08 & 57 \\
& Absolvido & 06 & 43 \\
\hline Indenização por & Materiais e morais & 05 & 62 \\
danos* $^{*}$ & Materiais & 01 & 13 \\
& Morais & 02 & 25 \\
Valor médio da & Não apresentado & - & - \\
indenização & R 11.794,99 & & \\
\hline Fonte: Elaborado pelos autores. Dados coletado do Tribunal de Justiça do Estado de São & Paulo (2015-2016).
\end{tabular}

Tabela 5- Distribuição numérica e porcentual do tipo de obrigação, da decisão judicial, da indenização por danos materiais e/ou morais ( ${ }^{*}$ considerando apenas os casos condenados) e o valor médio da indenização, para a especialidade Endodontia $(n=10)$.

\begin{tabular}{|c|c|c|c|}
\hline & & $\mathbf{N}$ & $\%$ \\
\hline \multirow[t]{3}{*}{ Tipo de obrigação } & Resultado & 05 & 50 \\
\hline & Meio & 03 & 30 \\
\hline & Não apresentado & 02 & 20 \\
\hline \multirow[t]{2}{*}{ Decisão judicial } & Condenado* & 04 & 37 \\
\hline & Absolvido & 07 & 63 \\
\hline \multirow{4}{*}{$\begin{array}{c}\text { Indenização por } \\
\text { danos }^{*}\end{array}$} & Materiais e morais & 01 & 25 \\
\hline & Materiais & - & - \\
\hline & Morais & 03 & 75 \\
\hline & Não apresentado & - & - \\
\hline $\begin{array}{l}\text { Valor médio da } \\
\text { indenização }\end{array}$ & $\mathrm{R} \$ 10.365,00$ & & \\
\hline
\end{tabular}

Fonte: Elaborado pelos autores. Dados coletado do Tribunal de Justiça do Estado de São Paulo (2015-2016).

Ao consultar o site do CFO, foi constatado que existiam $87.156 \mathrm{CDs}$ em atividade no estado de São Paulo e, ao aplicar a fórmula do coeficiente processual no estado de São Paulo, verificou-se que a cada $1.000 \mathrm{CDs}$ em atividade, 1,10 foi exposto a processo de responsabilidade civil no período de 2015- 2016. Em relação ao coeficiente processual por especialidade, os resultados estão apresentados na tabela 6 , sendo que a quantidade de especialistas por área (implantodontia, ortodontia, prótese, endodontia, cirurgia e periodontia) foi obtida no site do CROSP. 
Tabela 6- Distribuição numérica, porcentual e coeficiente de experiência processual das especialidades citadas e envolvidas nas decisões em processos civis contra CDs no estado de São

\begin{tabular}{ccccc} 
Especialidade & $\mathrm{N}^{*}$ & $\%$ & $\begin{array}{c}\text { Quantidade de } \\
\text { especialistas }\end{array}$ & $\begin{array}{c}\text { Coeficiente de } \\
\text { experiência } \\
\text { processual }\end{array}$ \\
\hline Implantodontia & 34 & 42 & $\mathbf{2 . 8 7 3}$ & $\mathbf{1 2 , 1 8}$ \\
Ortodontia & 15 & 20 & $\mathbf{5 . 3 3 0}$ & $\mathbf{2 , 8}$ \\
Prótese & 15 & 20 & $\mathbf{2 . 1 8 5}$ & $\mathbf{6 , 8 0}$ \\
Endodontia & 10 & 12 & 3.444 & $\mathbf{2 , 9 0}$ \\
Cirurgia & $\mathbf{5}$ & $\mathbf{5}$ & $\mathbf{1 . 6 0 4}$ & $\mathbf{3 , 1 1}$ \\
Periodontia & 1 & 1 & $\mathbf{2 . 6 0 9}$ & $\mathbf{0 , 3 9}$ \\
\hline TOTAL & 80 & 100 & 18.045 & 4,43
\end{tabular}

Fonte: Elaborado pelos autores. Dados coletado do *Tribunal de Justiça do Estado de São Paulo (2015-2016) e ${ }^{* *}$ Conselho Regional De Odontologia de São Paulo (2017).

\section{DISCUSSÃO}

O ato ilícito consiste na violação de direito alheio e na provocação de dano, ainda que apenas moral, por meio de uma ação ou omissão voluntária, negligência ou imprudência. A responsabilidade civil poderá ser subjetiva (quando houver culpa do agente, por imprudência, negligência e imperícia) ou objetiva (quando a atividade do agente é de risco). A regra geral do Código Civil Brasileiro (artigos 927 e 951) (BRASIL, 2002) e do Código de Defesa do Consumidor (\$4 do art. 14) (BRASIL, 1990) exigem a comprovação da culpa do agente (CD). Desse modo, o CD somente será responsabilizado civilmente por algum dano causado ao cliente, material ou moral, se for comprovada sua culpa. Quanto à obrigação, a relação contratual CD- paciente poderá ser de meio ou de resultado. Na obrigação de meio, o profissional se compromete a utilizar todos os meios para atingir o melhor resultado possível, mas, mesmo assim, nem sempre consegue tal finalidade, pois existem fatores que fogem ao controle do CD. Já na obrigação de resultado, é exigido o resultado final proposto na contratação do serviço e o não cumprimento do contrato poderá significar obrigação de indenização por parte do profissional (SILVA, 2010; MEDEIROS, COLTRI, 2014; DARUGE et al., 2017).

A escolha de centralizar o levantamento das decisões judiciais no estado de São Paulo foi decidida após análise do trabalho de Wanderley e Lima et al. (2012), que avaliaram 1.046 jurisprudências no período de 2006 a 2011 e constaram que o estado de São Paulo possuía a maior quantidade de processos de responsabilidade civil contra CD ( $n=374,35,76 \%)$, assim como no trabalho de Lyra et al. (2019). Observamos no levantamento dos acórdãos sobre a responsabilidade civil do CD no período de 2015-2016, que os magistrados consideraram em $51 \%$ dos casos que o tratamento odontológico apresentava responsabilidade subjetiva e em $34 \%$ dos casos esse dado não pode ser avaliado, pois tal informação não existia na decisão judicial. $\mathrm{Na}$ responsabilidade civil subjetiva, com base na teoria da culpa, pressupõe a culpa como fundamento. A prova da culpa, oriunda de um comportamento negligente, imprudente ou imperito do profissional, passa a ser pressuposto necessário ao dano indenizável (COELHO et al., 2012). Verificamos nesse trabalho que em $15 \%$ dos processos judiciais contra CD a responsabilidade civil foi considerada como objetiva. 
Na responsabilidade civil objetiva, a lei impõe a reparação de um dano cometido sem culpa, ou seja, satisfaz-se apenas com o dano e o nexo de causalidade entre atendimento odontológico e a lesão ocorrida. Nesse caso, a punição do CD num processo judicial possui a função pedagógica de prevenir novos prejuízos ou acidentes com outros pacientes (GONÇALVES et al., 2012). Importante observar que, atualmente, quase todas as atividades implicam em algum tipo de risco e, não tendo o legislador definido quais seriam estas atividades de risco, caberá à jurisprudência tal função (BERALDO et al., 2004).

No tratamento odontológico com obrigação de meio, o profissional vai empregar seus conhecimentos, meios e técnicas para a obtenção de determinado resultado sem, no entanto, prometê-lo, mas na obrigação de resultado o fim prometido deverá ser alcançado (GONÇALVES et al., 2012). As especialidades que tradicionalmente possuem obrigação de resultado são a dentística (principalmente envolvendo estética), a prótese dental, a radiologia, a implantodontia e a ortodontia (VENOSA, 2006). Atualmente a doutrina majoritária afirma ser de resultado a obrigação do $C D$, pois a etiologia dos problemas bucais seria específica, com diagnóstico mais definido e, consequentemente, os tratamentos seriam repetitivos e com resultados previsíveis. Infelizmente, os juízes se esqueceram de considerar, nessa questão, a resposta biológica do paciente, que não possui previsibilidade (SILVA et al., 2011; PRADO et al., 2016). Observamos nas decisões judiciais analisadas que no período de 2015 e 2016, os magistrados decidiram que o tratamento odontológico possuía obrigação de resultado em 49 casos $(52 \%)$ e obrigação de meio em 08 dos processos $(9 \%)$ analisados (tabela 1). Em 37 casos (39\%) essa informação não foi apresentada. No trabalho de Lyra et al. (2019) das 89 condenações, 49,44\% foram consideradas como obrigação de resultado e apenas $5,62 \%$ como de meio. Wanderley e Lima et al. (2012) também observaram que muitos parâmetros estabelecidos na pesquisa não puderam ser observados na análise dos processos judiciais. Esses autores detectaram que em $77,5 \%$ dos casos não foi possível a classificação do tipo de obrigação contratual do CD (se de meio ou resultado), assim como em relação ao tipo de responsabilidade, pois $70 \%$ das ementas não classificavam se a responsabilidade era objetiva ou subjetiva.

De modo geral, as especialidades odontológicas mais envolvidas em processo de responsabilidade civil foram implantodontia (42\%), ortodontia (20\%), prótese (20\%), endodontia (12\%) e cirurgia (5\%); o que está de acordo com os estudos de De Paula (2007) e Wanderley e Lima et al. (2012). Magalhães et al. (2019) constataram que as especialidades mais envolvidas nos casos de responsabilidade civil foram prótese dentária, ortodontia e implantodontia, nessa ordem. O trabalho de Lyra et al. (2019) citou, na sequência, as especialidades de prótese e implantodontia como as mais presentes e nos estudos de Zanin et al. (2016) se destacaram prótese, cirurgia oral maxilofacial, ortodontia e implantodontia. Lino- Júnior et al. (2017) apresentaram, sequencialmente, nas ações cíveis instauradas entre 2006 e 2015 as especialidades de cirurgia, endodontia, implantodontia, prótese e ortodontia. De modo geral, as especialidades de implantodontia, ortodontia e prótese vêm se destacando em estudos mais recentes (LYRA et al. 2019; MAGALHÃES et al. 2019). Em relação a obrigação de resultado, para cada tipo de especialidade (tabelas $2-5$ ), foi de $73 \%$ para implantodontia, $27 \%$ para a ortodontia, $36 \%$ para prótese e $50 \%$ para endodontia. Pelo princípio da indenidade, o juiz poderá determinar a inversão do ônus probatório com base no artigo 60, inciso VIII do Código de defesa do consumidor (BRASIL, 1990). Se o magistrado considerar no processo que o caso se trata de obrigação de resultado, pode-se considerar que a culpa é presumida e, portanto, inverte-se o ônus da prova e 
ao demandado (CD) compete demonstrar a inexistência de culpa para exonerar-se da obrigação, ou seja, o profissional deverá provar, em juízo, que não agiu com imprudência, imperícia ou negligência no desempenho de sua atividade; ou que a culpa foi exclusiva da vítima ou, ainda, o fato ocorreu por caso fortuito ou por força maior (DENARI, 2007; SILVA et al., 2010; KFOURI et al., 2019;). Ao analisarmos o período de 2015-2016, os juízes aplicaram a inversão do ônus da prova em 46 (49\%) das 94 decisões analisadas. Diante da possibilidade de inversão do ônus de prova, o CD precisa ter a consciência que o único meio de provar que agiu com prudência e diligência será por meio do prontuário odontológico bem elaborado. Dentre outros cuidados, deverá existir a atenção do profissional no preenchimento da ficha clínica em relação à escolha do plano de tratamento proposto ao paciente, orientações sobre o tratamento, assim como os detalhes das marcações nos odontogramas de antes e depois do tratamento executado. A elaboração do termo de consentimento do paciente sobre o tratamento proposto tornou-se importante na clínica diária, pois além de satisfazer as exigências do Código de defesa do consumidor, ainda demonstra a participação do paciente nas decisões do tratamento empreendido. A assinatura do paciente na evolução do tratamento, também comprova que a autonomia do paciente foi respeitada. Outros componentes do prontuário odontológico também colaborarão na defesa do profissional, quando bem executados e guardados, como as radiografias, os modelos de gesso, as fotos dos trabalhos executados e as cópias das recomendações de higiene oral e as orientações específicas de cada especialidade (SILVA et al., 2010; SILVA et al., 2011).

O valor da indenização é baseado na extensão do dano sofrido pela vítima. Ao condenar o ofensor, a lei busca o ressarcimento do prejuízo, mas a condenação também possui caráter pedagógico, que é a instrução ao culpado para não repetir a mesma situação. Os danos morais devem ser arbitrados pelo juiz tendo em consideração o sofrimento da vítima e às condições econômicas do ofensor e da vítima, não podendo gerar enriquecimento sem causa da vítima (TARTUCE, SARTORI, 2014). Nesse trabalho, o valor médio de indenização foi de 15 mil reais, relacionados a danos materiais e morais (64\%), apenas danos morais $(28 \%)$ ou apenas materiais (6\%). Zanin et al. (2016) detectaram que os danos pecuniários envolvidos nesse tipo de ação variaram de $R \$ 485,50$ a $R \$ 12.530,00$. No nosso trabalho, o valor de maior indenização foi de quase $\mathrm{R} \$ 37.000,00$, relacionado à especialidade de implantodontia, sendo que essa especialidade e esse valor também foram apresentados nos estudos de Zanin et al. (2016).

O coeficiente processual aplicado no estudo verificou que para cada $1.000 \mathrm{CDs}$ do estado de São Paulo 1,1 já foi julgado em processos de responsabilidade civil. Wanderley e Lima et al. (2012) obtiveram o valor de 5,76; mas esse dado estava relacionado à região sudeste e surgiu a partir de uma análise num período maior de tempo (6 anos). Em relação ao coeficiente processual por especialidade, foi possível constatar que para cada 1.000 implantodontistas, 12,18 foram expostos às ações de responsabilidade civil, e para as demais especialidades foram 2,80 para Ortodontia; 6,80 para Prótese; 2,90 para Endodontia; 3,11 para Cirurgia e 0,39 para Periodontia. No geral, para cada 1.000 especialistas, mais de quatro foram processados por seus pacientes, que exigiram indenização por danos materiais e/ou morais (Tabela 6).

\section{CONCLUSÃO}

Após a análise de 94 decisões judiciais relacionadas aos processos de responsabilidade civil contra CDs no estado de São Paulo no período de 2015 e 2016, 
podemos concluir que o tratamento odontológico foi considerado como de obrigação de resultado (52\%) com responsabilidade do tipo subjetiva $(51 \%)$, sendo que a inversão do ônus da prova ocorreu em $49 \%$ dos casos. O valor médio indenizatório foi de $\mathrm{R} \$ 15.657,78$ e implantodontia, a especialidade odontológica mais envolvida $(42 \%)$, seguida por Ortodontia (20\%), Prótese (20\%), Endodontia (12\%), Cirurgia (5\%) e Periodontia (1\%).

\section{REFERÊNCIAS}

BERALDO, L. F.A. Responsabilidade civil no Parágrafo único do Art. 927 do código civil e alguns apontamentos do direito comparado. Novos Estudos Jurídico NEJ., v. 9, n. 2, p. 317-40, 2004. DOI: http://dx.doi.org/10.14210/nej.v9n2.p317-340.

BRASIL. Lei n. 10.406, 10 de janeiro de 2002. Institui Código Civil. Brasília, DF: Presidência da República, 2002 Disponível em: http://www.planalto.gov.br/ccivil 03/leis/2002/l10406.htm. Acesso em: 22 ago. 2019.

BRASIL. Lei $\mathbf{n}^{\circ} \mathbf{8 0 7 8}$, de 11 de setembro de 1990. Código de Defesa do Consumidor. Dispõe sobre a proteção do consumidor e dá outras providências. Brasília, DF: Presidência da República, 1990. Disponível em: http://www.planalto.gov.br/ccivil 03/leis//80 78.htm. Acesso em: 30 mar. 2019.

COELHO, F.U. Curso de direito civil, volume 2: obrigações: responsabilidade civil. 5 ed. São Paulo: Saraiva, 2012.

CONSELHO REGIONAL DE ODONTOLOGIA DE SÃO PAULO. [Especialidades]. 2017. Disponível em: www.crosp.org.br. Acesso em: 10 mar. 2019.

DARUGE, E.; DARUGE JÚNIOR, E.; FRANCESQUINI JÚNIOR, L. Tratado de odontologia legal e deontologia. Rio de Janeiro: Guanabara Koogan; 2017.

DENARI, Z. Código Brasileiro de Defesa do Consumidor, comentado pelos autores do anteprojeto. 9 ed. São Paulo: Editora Forense, 2007.

DE PAULA, F.J. Levantamento das jurisprudências de processos de responsabilidade civil contra cirurgiões-dentistas nos tribunais do Brasil por meio da internet. 2007. (Tese de Doutorado). Faculdade de OdontologiaUniversidade de São Paulo, São Paulo, SP. 2007. 132 p. Disponível em: https://www.teses.usp.br/teses/disponiveis/23/23148/tde-10042008-183335/publico.

GONÇALVES, C. R. Direito civil esquematizado volume 1: parte geral das obrigações e contrato São Paulo: Saraiva, 2ed., 2012.

KFOURI NETO, M. Responsabilidade Civil do Médico. 10 ed. São Paulo: Editora Revista dos Tribunais, 2019.

LINO-JUNIOR, H.L. et al. Levantamento de processos de responsabilidade civil envolvendo a odontologia na comarca de Londrina, Paraná, Brasil. Rev. Jurídica, v. 1, n. 146, p. 515- 31, 2017. Doi: http://dx.doi.org/10.6084/m9.figshare.558176 5. 
LYRA, M.C.A.R.; PEREIRA, M.M.F.A.; MUSSE, J.O. A obrigação de resultado nas ações de responsabilidade civil do cirurgião-dentista no Brasil, em 2017. Rev Bras Odontol Leg RBOL, v. 6, n. 3, p. 47-58, 2019.

MAGALHÃES, L.V.; COSTA, P.B.; SILVA, R.H.A. Análise dos processos indenizatórios envolvendo a odontologia na grande vitória, Espírito Santo, Brasil. Rev Bras Odontol Leg RBOL, v. 6, n. 2, p. 13-20, 2019.

MEDEIROS, U.V.; COLTRI, A.R. Responsabilidade civil do cirurgião-dentista. Rev. Bras. Odontol., v. 71, n.1, p. 10-6, 2014.

NEVES, H.M.; CANETTIERI, A.C.V. Levantamento da jurisprudência nas ações de responsabilidade civil contra cirurgiões dentistas no estado de São Paulo. In: ENCONTRO LATINO AMERICANO DE INICIAÇÃO CIENTÍFICA, 21., 2017, São José dos Campos. Anais eletrônico [...]. São Jose dos Campos: Univap, 2017. Disponível em:

http://www.inicepg.univap.br/cd/INIC 2017/anais/arquivos/RE 05290188 01.pdf. Acesso em: 30 nov. 2020.

OLIVEIRA, C.M.L. et al. Processos movidos contra cirurgiões-dentistas no Conselho Regional de Odontologia - seção Pará - nos últimos sete anos. Saúde, Ética Justiça, v. 15, n. 2, p. 46-52, 2010. Disponível em:

http://www.revistas.usp.br/sej/article/view/45764/49356. Acesso em: 24 abr. 2019.

PRADO, M,M. et al. Ortodontia e a interpretação de sua natureza obrigacional: análise do potencial de impacto de uma decisão do Superior Tribunal de Justiça (STJ). Rev. Bras. Odontol Leg RBOL, v. 3, n. 2, p. 53-65, 2016. DOI: http://dx.doi.org/10.21117/rbol.v3i2.

SÃO PAULO, Tribunal de Justiça. [Processos]. 2015-2016. Disponível em: http://www.tjsp.jus.br Acesso em: 10 mar. 2019.

SILVA, M.; ZIMMERMANN, R.D.; DE PAULA, F.J. Deontologia odontológica: ética e legislação. São Paulo: Santos, 2011.

SILVA, R.H.A. et al. Responsabilidade civil do cirurgião-dentista: a importância do assistente técnico. Rev. Dent. Press. Ortodon. Ortop. Facial, Maringá, v. 14, n. 6 , p. 65-71, nov/dez, 2009. Disponível em: http://www.scielo.br/pdf/dpress/v14n6/a09v14n6.pdf. Acesso em: 9 fev. 2019

SILVA, R.H.A. Orientação profissional para cirurgião-dentista: ética e legislação. São Paulo: Santos, 2010.

TARTUCE, F.; SARTORI, F. Como se preparar para o exame de Ordem. 12. ed. São Paulo: Método, 2014.

VENOSA, S.S. Direito Civil: Responsabilidade Civil. São Paulo: Atlas; 2006.

ZANIN, A.A.; HERRERA, L.M.; MELANI, R.F.H. Civil liability: characterization of the demand for lawsuits against dentists. Braz Oral Res., v. 30, n. 1, p. 1-8, 2016. DOI: 
http://dx.doi.org/10.1590/1807-3107BOR2016.vol30.0091.

WANDERLEY E LIMA, R.B. et al. Levantamento das Jurisprudências de Processos de Responsabilidade Civil Contra Cirurgiões-Dentistas nos Tribunais de Justiça Brasileiro. R. Bras. Ci. Saúde, João Pessoa, v. 16, n. 1, p. 49-58, 2012. Disponível em: https://periodicos.ufpb.br/ojs/index.php/rbcs/article/view/12262. Acesso em: 10 mar. 2019. 